\title{
Does Test-Anxiety Experience Impair Student Teachers' Later Tendency to Perspective-Taking?
}

\author{
Anett Wolgast - Miriam Hille - Philipp Streit - \\ Wolfgang Grützemann*
}

\author{
Received: October 30, 2019; received in revised form: January 11, 2020; \\ accepted: january 13, 2020
}

\begin{abstract}
:
Introduction: We aimed to examine whether student teachers' tendency to test anxiety relates to their later perspective-taking tendency and selfefficacy. The purpose of the presented study was to obtain first insights into the relationship between test anxiety, perspective-taking, and selfefficacy tendencies in student teachers. These tendencies may determine student orientation across different situations. We tested the hypothesis that the test anxiety components emotionality and worry relate to later low perspective-taking and self-efficacy.

Methods: We conducted a longitudinal study with 275 student-teachers and analyzed the obtained data using structural equation modeling.

Results: The data analysis revealed that only emotionality is related to lower perspective-taking and self-efficacy in later life.

Discussion: We conclude that lowering student teachers' test anxiety emotionality (e.g. through interventions) would result to later increased perspective-taking tendency.

Limitations: Participants attended the study voluntarily, so it was a selfselected sample. We employed a correlational design over two measurement times instead of experimental methods.

Conclusions: The obtained results give an explanation of why student teachers focused rather on themselves than on school students in classes. The perspective-taking tendency is important for teachers' student
\end{abstract}

\footnotetext{
"Anett Wolgast, Martin-Luther-University Halle-Wittenberg, Institute of Education, Halle, Germany; anett.wolgast@gmail.com

Miriam Hille, Martin-Luther-University Halle-Wittenberg, Institute of Education, Halle, Germany; miriam.hille@student.uni-halle.de

Philipp Streit, Martin-Luther-University Halle-Wittenberg, Institute of Education, Halle, Germany; philipp.streit@ paedagogik.uni-halle.de

Wolfgang Grützemann, Martin-Luther-University Halle-Wittenberg, Institute of Education, Halle, Germany; wolfgang.gruetzemann@paedagogik.uni.halle.de
} 


\section{Acta Educationis Generalis \\ Volume 10, 2020, Issue 1}

orientation. The role of perspective-taking in different teaching situations might be investigated in further research.

Key words: student teachers; emotionality; worry; test anxiety; perspective-taking.

\section{Introduction}

Teachers' empathic responses to students, interpersonal understanding, and constructive handling of conflict situations (e.g. Tamášová \& Barnová, 2011) with students are precursors of students' learning and academic achievement (e.g. Gehlbach, 2004). These precursors are potentially related to self-efficacy a well-known resource for teachers' well-being (see Zee \& Koomen, 2016, for a research synthesis over 40 years). Indeed, teachers should apply their content knowledge, pedagogical content knowledge, and pedagogical knowledge (e.g. Shulman, 1987) to engage in student-oriented teaching as often as possible. Student-oriented teaching is stipulated in Germany's national teaching standards (Standing Conference of the Ministers of Education and Cultural Affairs of the Länder in the Federal Republic of Germany, 2014). Other national education standards (e.g. Every Student Succeeds Act, U.S. Department of Education, 2019) require teachers to consider students' diverse learning prerequisites and socially appropriate teacher-student interactions. In essence, these standards from Germany and the United States demand that teachers pay attention to their students in class.

Scholars have discussed paying attention to others and socially appropriate responses in light of emotional intelligence (e.g., Uitto, Jokikokko, \& Estola, 2015), empathy (e.g. Gáborová, 2011; Mattan, Rotshtein, \& Quinn, 2016; Ütkür, 2019), or perspective-taking tendency. Several studies have found significantly positive relations at mild to moderate levels between perspective-taking tendency (personality trait approach, e.g. Davis, 1980) and processing social perspective-taking (state approach, e.g. Mattan et al., 2016).

Social perspective-taking involves making assumptions about a target person's self - his or her abilities, interests, beliefs, values, goals or habits - as if one were the target person. The assumption and understanding that people have different knowledge and different thoughts and therefore act differently is known as the 'theory of mind' (e.g. Baron-Cohen, Wheelwright, Hill, Raste, \& Plumb, 2001). The concept of theory of mind has been widely studied, particularly regarding its development in children with and without autism spectrum disorder (e.g. BaronCohen et al., 2001). That is, an individual can only understand deviations between him or her own desires or intentions and a target person's desire and intentions when he or she knows that the target person, and other people as well, has individual desires or intentions that may differ from his or her own. The 


\section{Acta Educationis Generalis \\ Volume 10, 2020, Issue 1}

ability to understand this deviation is necessary for developing perspectivetaking tendency (Schaafsma, Pfaff, Spunt, \& Adolphs, 2015).

For example, teachers with high tendency to perspective-taking are motivated to collect information about different situations in order to better understand the students' intentions or actions (e.g. Gehlbach \& Vriesema, 2019) because they expect different intentions in different students. In this way, the teachers attempt to discern cognitive processes in their students that are not actually visible. Another example occurs when teachers attempt to understand how students construct the meaning of a subject-related concept (e.g. light or light reflection). The teachers might ask questions of their students to discern their misconceptions (arrows instead of light waves) and inferring from their answers what kind of support would help to stimulate their development of new concepts (e.g. that light moves in waves).

Perspective-taking tendency is related to several external and internal factors that are likewise important for (student) teachers. For example, it is positively correlated with a student orientation (e.g. Kordts-Freudinger, 2017) and selfefficacy (e.g. Zee \& Koomen, 2016). The latter has been found to be a resource for (student) teachers' well-being (e.g. Zee \& Koomen, 2016).

Self-efficacy is associated with an individual's expectancy (e.g. Bandura, 1977; Wigfield \& Eccles, 2000) directed to the next moment or future. Academic selfefficacy refers to the expectancy of solving a task, passing an exam or achieving other kinds of academic success (e.g. Schwarzer \& Jerusalem, 1999). Social selfefficacy refers to individuals' expectations with respect to their ability to deal with social situations, especially conflict situations, and their subjectively perceived success in such situations. Previous studies have repeatedly shown that student teachers' and teachers' self-efficacy can be considered an intraindividual resource (e.g. Barnová, Tamášová, \& Krásna, 2019) that is related to low test anxiety (e.g. Barrows, Dunn, \& Lloyd, 2013; Roick \& Ringeisen, 2017).

Findings from other studies have even indicated relationships between teachers' social behavior and students' learning prerequisites. Students who perceived attention, monitoring, and rule clarity on the part of their teachers reported higher interest in math than students who did not perceive these forms of student orientation from their teacher (Kunter, Baumert, \& Köller, 2007).

Like interest, anxiety is another learning prerequisite among students. However, teachers were found to overlook the symptoms of students' anxiety in a nomination task (Bilz, 2014). The students' symptoms were assessed by the Strengths and Difficulties Questionnaire (SDQ, Goodman, 1997). We therefore ask the following question: Which factors facilitate or hinder teachers' discernment and understanding of learning prerequisites such as anxiety among all students in class (with and without additional needs)? One possible reason for (student) teachers' weaker student orientation might be their own anxiety. Student teachers engaged in practice teaching in schools and even in-service 


\section{Acta Educationis Generalis \\ Volume 10, 2020, Issue 1}

teachers (e.g. Sinclair \& Ryan, 1987) may experience anxiety in class (e.g. Frenzel et al., 2016). Teachers' self-reported distress is related to higher selfreported anxiety (e.g. Van Droogenbroeck \& Spruyt, 2015) and lower selfreported perspective-taking (Kordts-Freudinger, 2017). In addition, higher levels of the general tendency to anxiety known as neuroticism are related to low selfreported perspective-taking (e.g. Mooradian, Davis, \& Matzler, 2011). However, there is still a research gap regarding whether and to what extent test anxiety relates to student teachers' later perspective-taking tendency. Research on teachers' perspective-taking tendency is important because it might facilitate student-oriented teaching.

We assumed that perspective-taking tendency is fundamental to teachers' student orientation (e.g. Kordts-Freudinger, 2017), discernment (e.g. Gehlbach \& Vriesema, 2019) and understanding of the students' learning prerequisites (e.g. symptoms of anxiety, Bilz, 2014), and handling of conflict situations (e.g. Davis, 1980). We further assumed that test anxiety is related to low perspectivetaking tendency and that the latter is a further resource for student teachers in achievement test situations in addition to already evident resources (e.g. selfefficacy). We therefore expected, high perspective-taking tendency is to be related to high self-efficacy.

In the current study, test anxiety and perspective-taking tendencies are considered as personality traits that are associated with behavior across different situations (e.g. Sinclair \& Ryan, 1987), such as student teachers' practice teaching in school classes. Note that personality traits may change in a relatively short time (four weeks or a few months) through interventions, as Roberts et al. (2017) synthesized in their meta-analytical review. Similar to an intervention, practical teaching experiences in schools, university lectures and courses can all affect students' traits.

We aimed to extend the findings presented above (e.g. Davis, 1980; Gehlbach, 2004; Zee \& Koomen, 2016) and close the existing research gap by examining whether student teachers' test anxiety tendency relates to their later perspectivetaking tendency and self-efficacy. To enrich our correlational design, we also included further variables found to be relevant in existing theoretical frameworks and previous research findings (e.g. Pekrun, 1984, 2006; Wigfield $\&$ Eccles, 2000). These are outlined in the following sections.

\section{Components of test anxiety}

Test anxiety is described as a construct with an affective and a cognitive component (e.g. Hodapp, Laux, \& Spielberger, 1982; Zeidner, 1998) and sometimes further components as well (e.g. Frenzel et al., 2016; Pekrun, 2006; Scherer, 1984). Examples of further test anxiety components are: motivation (e.g. avoidance goal orientation), expressions (e.g. anxious facial expression), and physiological reactions (e.g. increased heart rate and blood pressure). However, there is broad agreement concerning the existence of an affective 


\section{Acta Educationis Generalis \\ Volume 10, 2020, Issue 1}

component (e.g. emotionality, feelings of nervousness) and a cognitive component (e.g. worry, Szafranski, Barrera, \& Norton, 2012; Zeidner, 1998).

Emotionality and worry in test anxiety are linked to the expected test outcome, such as failing or passing an exam. In addition, experiences with failing an exam and the associated short- or long-term negative consequences (e.g. Pekrun, 2006) may increase test anxiety (emotionality and worry, e.g. Zeidner, 1998) before upcoming exams. In the current study, we applied the classical two-component conceptualization of test anxiety (Hodapp et al., 1982). In this approach, emotionality refers to self-reported physiological and emotional states, such as detecting one's heart beating faster or excitement (e.g. Hodapp et al., 1982).

The worry, the cognitive component, involves thinking about the personal and social consequences of failing an exam. Worry requires cognitive resources, which are then no longer available for test performance. A student teacher experiences control with regard to an upcoming exam when he or she expects that he or she can positively influence the test outcome by studying and practicing the types of tasks that will appear on it. Academic self-efficacy refers to subject beliefs that one has a high probability of solving all tasks before and during the exam (e.g. Bandura, 1977; Zee \& Koomen, 2016). Most exam tasks are usually unknown prior to test taking, so a certain degree of subjective uncertainty about passing the upcoming exam will remain even when a student studies and practices as best they can.

Mooradian et al. (2011) examined self-reported emotionality and worry within the test anxiety framework and found that both were related to high neuroticism. Furthermore, self-reported test anxiety was related to high levels of self-reported social anxiety and to situational emotionality/worry before or during an exam (state test anxiety, e.g. Bolger \& Eckenrode, 1991). Interestingly, socially anxious undergraduates with experimentally induced worry (Zainal \& Newman, 2018) outperformed controls in the reading-the-mind-in-the-eyes test (RMET; Baron-Cohen et al., 2001). Moreover, gender differences existed: Female undergraduates scored higher than male undergraduates on both emotionality and worry (e.g. Farooqi, Ghani, \& Spielberger, 2012). Test anxiety prevalence among German undergraduate students in 2016 was about 12\% (Middendorff, Apolinarski, Becker, Bornkessel, Brandt, Heißenberg, \& Poskowsky, 2017). Although high levels of self-reported test emotionality and worry have been related to various impairments in achievement situations (e.g. Barrows et al., 2013), to our knowledge, no findings exist about the relationships with student teachers' perspective-taking tendency - the assumed precursor of their later student orientation in class. 


\section{Acta Educationis Generalis \\ Volume 10, 2020, Issue 1}

\section{Theoretical framework}

Several theories address students' academic test anxiety. One approach is the control value theory of achievement emotions, which Pekrun (2006) developed on the basis of previous theoretical frameworks, such as the expectancy value model of anxiety and the framework of individuals' perceived control (Pekrun, 1984). His control value theory focuses on explaining test anxiety (Pekrun, 2006). If one perceives a lack of control and focuses on failure while studying for an exam, the probability of test anxiety is assumed to increase (e.g. Pekrun, 1984, 2006). In later research, some scholars have explained undergraduates' test anxiety with the control value approach (e.g. Roick \& Ringeisen, 2017). Other authors have explained undergraduates' test anxiety (e.g. Xu, 2017) with the expectancy-value model proposed by Wigfield and Eccles (2000). The expectancy-value model assumes that subjective academic values correspond with expectancies of failing or passing an exam (Wigfield \& Eccles, 2000). High-stakes tests are subjectively important for student teachers and other testtakers. Consequently, both higher academic expectations about success and higher failure anxiety can be expected in high-stakes tests compared to lowstakes tests. Expectations have been also considered part of appraisals in control value theory and supporting empirical research (e.g. Pekrun, 2006). Academic expectations are often operationalized by assessing academic self-efficacy. Statements assessing perspective-taking tendency at least partially capture social relations and interactions.

Since we were interested in explaining student teachers' perspective-taking tendency and its relation to their self-efficacy, as introduced above, we mainly followed Davis' model, depicted in Figure 1. It outlines in a simple and concise way the complex relations between the person, situation, tend to make accurate assumptions about a target person (perspective-taking as "Non-Affective Outcomes", Davis, 2018, p. 13), and possible empathetic responses to the target. Taken together, previous study results (e.g. Kordts-Freudinger, 2017) suggest that perspective-taking tendency is a personal resource in dealing with one's own emotionality and worry within the test anxiety framework. However, the relationships between student teachers' self-reported test anxiety, specifically the components emotionality or worry; later perspective-taking; and self-efficacy have not yet been sufficiently researched. 


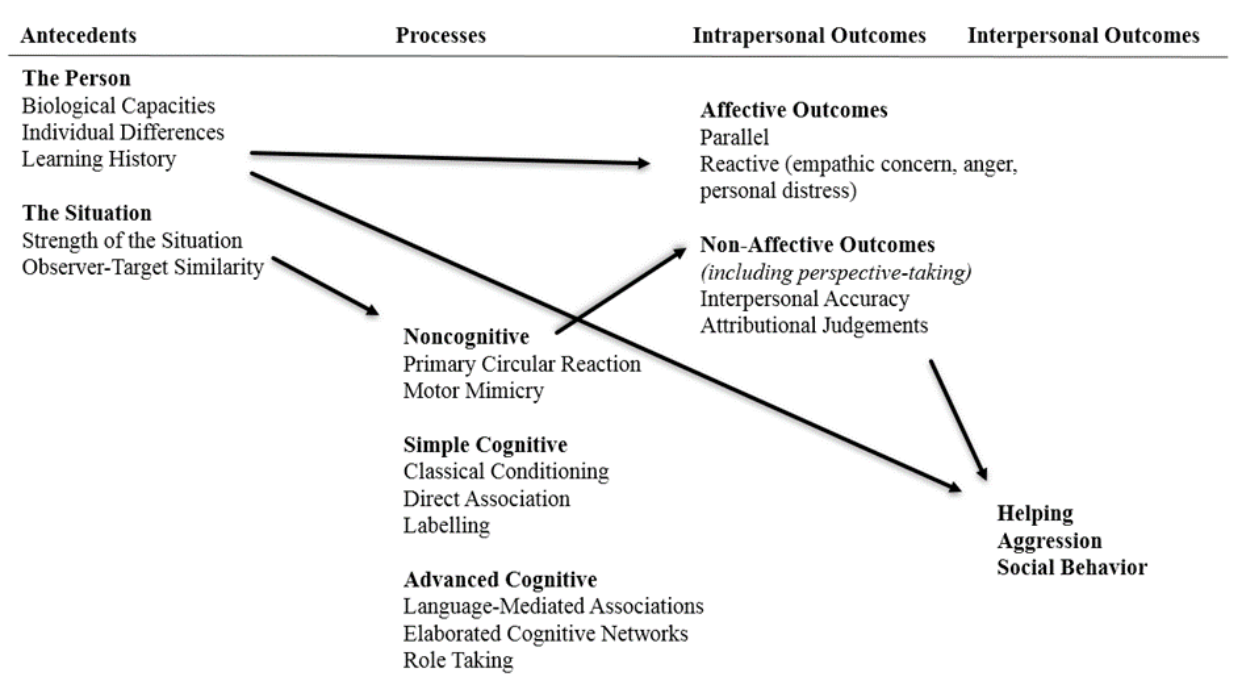

Note. The model considers antecedents such as characteristics of the person (biological capacities, individual differences, learning history) and the situation (strength of situation, observer-target similarity), noncognitive (primary circular reaction, motor mimicry), simple cognitive (conditioning, associations, labelling), and advanced cognitive processes (mediated associations, elaborated networks, role taking). Furthermore, the model distinguishes between intrapersonal (empathic concern, anger, personal distress, attributional judgements) and interpersonal outcomes (helping, aggression, social behavior) (Davis, 2018, p. 13).

Figure 1. The organizational model of empathetic responses and social behavior.

\section{Further relevant variables}

Further variables of potential relevance for the relations between test anxiety, perspective-taking tendency, and self-efficacy should also be considered due to the correlation study design. Previous research suggests that gender (e.g. Gerwing, Rash, Gerwing, Bramble, \& Landine, 2015), grade point average in school (e.g. Zeidner, 1998), and neuroticism (e.g. Malone \& Bertsch, 2016, Mooradian et al., 2011) are relevant for test anxiety. Females have been found to report higher levels of emotionality and worry with regard to exams than males (e.g. Gerwing et al., 2015). Neuroticism is positively related to test anxiety (e.g. Malone \& Bertsch, 2016, Mooradian et al., 2011), as already introduced above. Konrath, O'Brien, and Hsing (2011) described that perspective-taking tendency follows inverted u-curve with regard to age. In another longitudinal study, females' perspective-taking tendency was significantly higher than males' tendency at six measurement points (Van der Graaff et al., 2014).

However, there is little evidence on whether a study semester, the number of completed courses, or individual learning outside of courses relate to 


\section{Acta Educationis Generalis \\ Volume 10, 2020, Issue 1}

undergraduates' test anxiety and perspective-taking tendencies. We thus considered these variables as well in the current study to explore their relevance for self-reported test anxiety, perspective-taking and self-efficacy. Based on findings from previous research and possible relations to further relevant variables (e.g. Gerwing et al., 2015; Konrath et al., 2011; Malone \& Bertsch, 2016, Mooradian et al., 2011; Van der Graaff et al., 2014), we calculated structural equation models (SEM) including the variables gender, grade point average in school, and neuroticism.

\section{The current study}

Research questions derived from the Davis' model (see Figure 1), control value theory (Pekrun, 2006), and the research summarized in Section 1 were as follows: (1) What proportion of student teachers in an illustrative sample from the field of teacher education exhibit test anxiety tendency (emotionality/worry)? Does a high tendency to exhibit emotionality or worry affect student teachers' later (2) perspective-taking tendency or (3) self-efficacy when the further relevant variables are included as predictors at $\mathrm{T} 1$ in structural equation models (i.e. gender, age, grade point average, study semester, the number of attended courses, hours spent studying individually per week, neuroticism, academic/social self-efficacy, perspective-taking at T1)?

Our predictions were as follows: (1) Up to 20\% of student teachers will indicate a test anxiety tendency (emotionality/worry). (2) Student teachers' test anxiety (emotionality/worry) will be negatively related to perspective-taking tendency assessed several months later (controlling for the further relevant variables). (3) Self-reported emotionality and worry will be negatively related to student teachers' self-efficacy assessed several months later (again controlling for the further relevant variables). We expected results suggesting that both perspectivetaking tendency and self-efficacy are possible resources in dealing with emotionality and worry before an upcoming exam.

\section{Method}

\subsection{Participants}

The sample for the longitudinal analyses consisted of $\mathrm{N}=257$ student teachers (78\% female) from Martin-Luther-University Halle-Wittenberg in Germany. Anonymity was protected by using participant ID numbers. Seven cases with missing ID values were excluded from the longitudinal analysis and one case was excluded because the participant was enrolled in a study program outside teacher education. All of the remaining $n=249$ participants were undergraduates in teacher education who had been studying for 4.86 semesters on average $(\mathrm{SD}=2.79)$. According to university statistics from 2018 (Martin-LutherUniversity, not published; see https://www.daad.de/en/information-services-for- 


\section{Acta Educationis Generalis \\ Volume 10, 2020, Issue 1}

higher-education-institutions/further-information-on-daad-programmes/ lehramtinternational/) the number of student teachers from abroad or with an ethnic background other than German was below 1\%. Due to this small number, we did not explicitly ask about participants' ethnic background. Data were collected in the context of educational psychology courses. The first measurement point was during the summer term (T1, N=943) and the second during the following winter term about five months later (T2, N=1058). An acceptable number of student teachers participated twice, yielding the longitudinal dataset. However, many student teachers only participated once at either T1 or T2, and their cross-sectional data were excluded from the analyses (see Appendix A for tests for possible differences between the included longitudinal data and the excluded cross-sectional data).

\subsection{Procedure}

The student teachers participated in our study voluntarily. They received and answered a questionnaire during courses on research in teacher education. The questionnaire began with items assessing different constructs, including items on the test anxiety components of emotionality (e.g. Hodapp et al., 1982) and worry (Schwarzer \& Jerusalem, 1999), perspective-taking (Davis, 1980), self-efficacy (Schwarzer \& Jerusalem, 1999), and neuroticism (Rammstedt et al., 2004) in randomized order. Afterwards, a few background questions followed regarding the participants' gender, age, and study program (e.g. teaching in special education, in elementary school, lower- or middle-track secondary school, vocational school, or an academic-track secondary school, i.e., Gymnasium). The participants were able to complete the entire questionnaire within 30 minutes.

\subsection{Instruments}

We presented each of the self-report measures described below on a 5-point scale ( $1=$ not true at all to $5=$ completely true) in German. The item order within the questionnaire was randomized, with the exception that the demographic background questions always occurred at the end.

\section{Test anxiety}

We used four statements to assess student teachers' emotionality at T1, three of which came from the Test Anxiety Inventory (TAI) (Hodapp et al., 1982) and the fourth constructed by Schwarzer and Jerusalem (1999). Participants indicated whether they experienced physical and emotional symptoms of test anxiety in the face of an upcoming exam. The emotionality statements were introduced with the question: How do you feel when you are about to take an exam? (e.g. I am excited. - translated from German for the purposes of this paper). Internal consistency (Cronbach's alpha) was satisfactory $(\alpha=.86)$. The five items (Schwarzer \& Jerusalem, 1999) assessed the test anxiety dimension 


\section{Acta Educationis Generalis \\ Volume 10, 2020, Issue 1}

worry at T1, for example: I wonder if my exam performance will be sufficient $(\alpha=.87)$. Both emotionality and worry served as predictor variables in the SEM.

\section{Perspective-taking tendency}

Four statements from the Interpersonal Reactivity Index (Davis, 1980) assessed perspective-taking tendency. The statements were introduced with the question: To what extent do the following statements apply to you? Participants indicated how they would act in social situations involving self-reflective and reciprocal perspectives. An example item is: I believe that there are two sides to every question and try to look at them both. We included the construct assessed at T1 $(\alpha=.80)$ as a predictor variable and at $\mathrm{T} 2(\alpha=.83)$ as an outcome variable in the SEM.

\section{Self-efficacy}

We adapted nine statements developed by Schwarzer and Jerusalem (1999) to measure self-efficacy. Five items were used to measure the undergraduates' academic self-efficacy (e.g. It is easy for me to understand new learning materials, T1 $\alpha=.64, \mathrm{~T} 2 \alpha=.66$ ) and four items to measure social self-efficacy (e.g. I easily find new friends even in a new group, T1 $\alpha=67, \mathrm{~T} 2 \alpha=.68$ ). Both self-efficacy factors assessed at $\mathrm{T} 1$ were included as predictor variables and at $\mathrm{T} 2$ as outcome variables in the SEM.

\section{Further relevant variables}

The correlation study design as well as previous research findings (e.g., Gerwing et al., 2015; Konrath et al., 2011; Malone \& Bertsch, 2016, Mooradian et al., 2011; Van der Graaff et al., 2014) suggested that we ought to consider further variables in the statistical modeling, as outlined in Section 3.2. We included the variables age, gender, study semester, socioeconomic status, use of learning opportunities in the teacher education program, and school achievement. In the present study, these variables, perspective-taking, and self-efficacy assessed at $\mathrm{T} 1$ were specified as predictor variables in order to account for their contribution to the outcome variables perspective-taking and self-efficacy at T2. We further included factor neuroticism at T1, constructed on the basis of four items (Rammstedt, Koch, Borg, \& Reitz, 2004), as a predictor variable on the outcome variables at $\mathrm{T} 2$.

Participants' age was assessed in categories for anonymity reasons, as described above in Section 2.1. Male student teachers were coded as 0 , females as 1 . The students' semester of studies was assessed as a discrete integer. The undergraduate study program was treated as a categorical variable (as described above in Section 2.1.). The use of learning opportunities was assessed with the number of credit hours taken in the current semester. Grade point average in school served as an indicator of previous academic achievement. The questionnaire also comprised further instruments (see Appendix A for a 


\section{Acta Educationis Generalis \\ Volume 10, 2020, Issue 1}

complete list of measures used in survey) that we excluded from the current analyses due to their lack of relevance for the current study.

\section{Analysis strategy}

An a-priori sample size calculation for structural equation models (https://www. danielsoper.com/statcalc/calculator.aspx ?id=89) with an anticipated effect size of $h=0.25$, adjusted from the effects found in previous research on anxiety and theory-of-mind performance (Zainal \& Newman, 2018), yielded a required sample size of at least 281 participants to achieve a $80 \%$ power and enable the detection of effects between test anxiety and perspective-taking. Compared to the a-priori sample size calculation, our sample size for analyses $(n=249)$ was fairly small. Hence, we set the significance level at $\alpha \leq .05$.

\subsection{Missing values}

The missing values for the dependent variables perspective-taking and selfefficacy across the two measurement points were $0 \%$ and $0.4 \%$ of $n=249$ respectively. The other used variables contained from $0 \%$ up to $1.6 \%$ missing values. Table 1 shows the absolute numbers of missing values.

Table 1

Means, standard deviations, range, and missing values in emotionality, worry, perspective-taking, self-efficacy, and neuroticism tendencies at Time 1 (T1) and Time 2 (T2)

\begin{tabular}{lcccc}
\hline & $\underline{M}$ & $\underline{S D}$ & $\underline{\text { Range }}$ & $\underline{\text { Missing values }}$ \\
1 Emotionality, T1 & 3.38 & 0.87 & $1.20-5.00$ & 3 \\
2 Worry, T1 & 3.06 & 0.90 & $1.00-5.00$ & 3 \\
3 Perspective-taking, T1 & 3.92 & 0.58 & $1.75-5.00$ & 2 \\
4 Academic self-efficacy, T1 & 3.77 & 0.45 & $2.20-5.00$ & 3 \\
5 Social self-efficacy, T1 & 3.72 & 0.57 & $2.00-5.00$ & 1 \\
\hline 6 Perspective-taking, T2 & 3.90 & 0.58 & $2.00-5.00$ & 3 \\
7 Academic self-efficacy, T2 & 3.80 & 0.44 & $2.40-5.00$ & 5 \\
8 Social self-efficacy, T2 & 3.76 & 0.53 & $2.25-5.00$ & 2 \\
9 Neuroticism, T1 & 2.92 & 0.74 & $1.30-5.00$ & 3
\end{tabular}

Note. Emotionality and worry are considered components of test anxiety tendency. Ranges are specified with regard to the five-point rating scale. 


\section{Acta Educationis Generalis \\ Volume 10, 2020, Issue 1}

\subsection{Structural equation modeling (SEM)}

First, we conducted a confirmatory factor analysis (CFA) with a nine-factor model, including all self-report items described in Section 2.2 as indicators measuring the latent factors emotionality and worry at $\mathrm{T} 1$, neuroticism at $\mathrm{T} 1$, and perspective-taking, academic and social self-efficacy tendencies at $\mathrm{T} 1$ and T2. The constructed model is depicted in Figure 2.

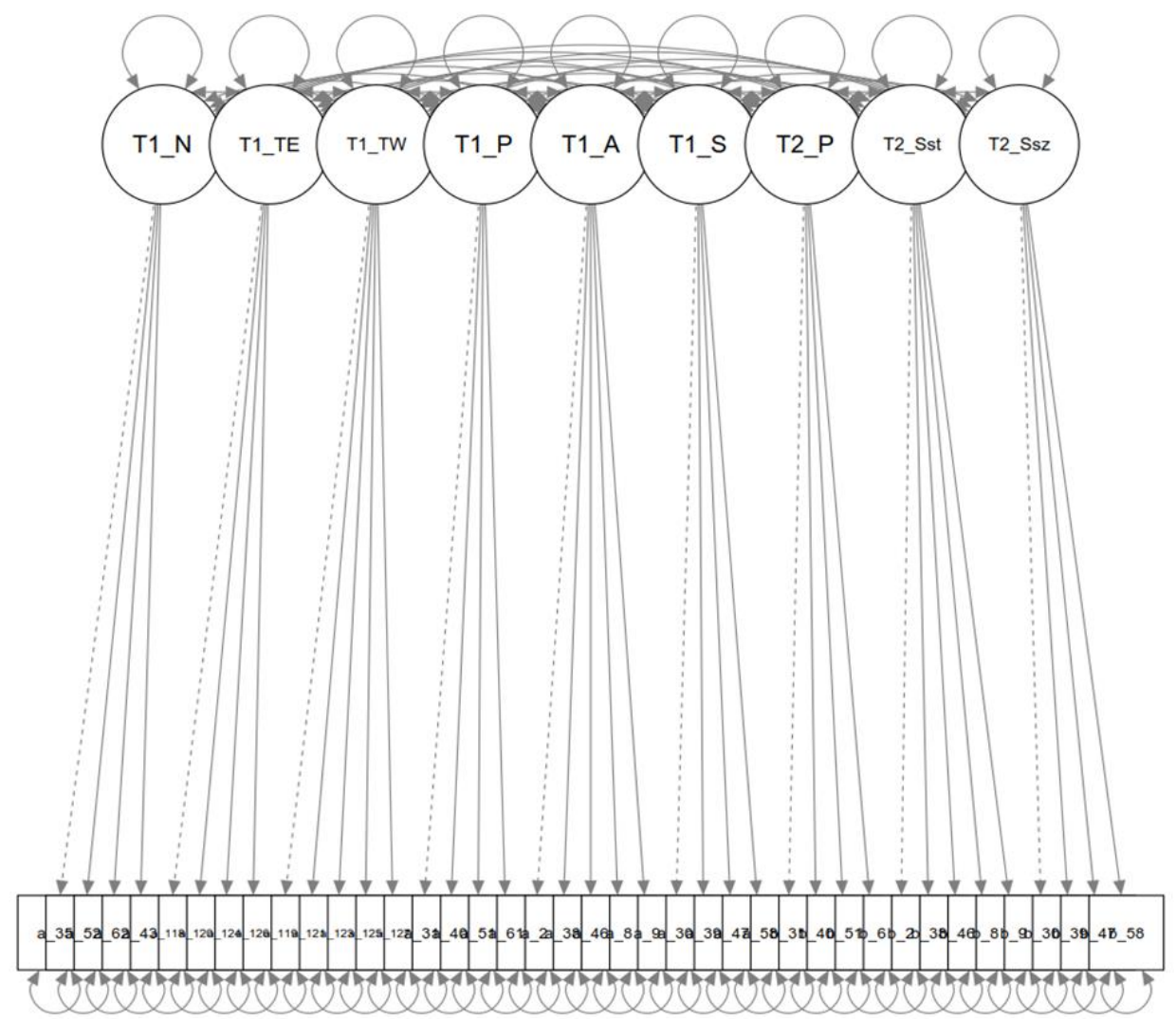

Note. $\mathrm{N}=$ neuroticism, test anxiety components $\mathrm{TE}=$ emotionality, $\mathrm{TW}=$ test worry; $\mathrm{PT}=$ perspective-taking tendency, $\mathrm{ASE}=$ academic self-efficacy, $\mathrm{SSE}=$ social selfefficacy as measured by the items below the circled latent factors.

Figure 2. CFA model.

The CFA (R package lavaan; Rosseel, 2012) indicated an acceptable fit between the assumed model and the structure found in our data, $\chi 2(666)=686.22, p=.29$, Further fit statistics were as follows: root mean square error of approximation $($ RMSEA $)=.01$, C.I. $[<.01, .02]$, comparative fit index $(\mathrm{CFI})=.99$, standardized root mean square residual (SRMR=.07) using weighted least square of mean 


\section{Acta Educationis Generalis \\ Volume 10, 2020, Issue 1}

variance estimation (WLSMV). We then tested for measurement invariance over time by including the factors measured at T1 and T2 (i.e. perspective-taking, academic and social self-efficacy). This test suggested equivalent factor loadings and means over five months according to suggested cut-off values by Rutkowski and Svetina (2014): fit-means $\chi^{2}(294)=414.84, p=.07, \Delta$ CFI $=.01 \quad$ (scalar invariance). Detailed invariance test results are not provided for reasons of space and can be obtained from the corresponding author upon request. We then constructed the SEM (R package lavaan, Rosseel, 2012) by extending the CFA model (see Figure 2) to include the predictor variables emotionality, worry, perspective-taking, academic and social self-efficacy, neuroticism, age, gender, school achievement, number of semesters, the number of attended courses, and individual learning hours outside courses, all at T1.

\section{Results}

The correlations are presented in Table 2 .

Table 2

Latent correlations in SEM between the constructed factors for neuroticism, the test anxiety components emotionality and worry, perspective-taking, and selfefficacy

1 Neuroticism at $\mathrm{T} 1$

2 Emotionality at $\mathrm{T} 1$

3 Worry at T1

4 Perspective-taking, T1, T2

$\begin{array}{llllll}\underline{1} & \underline{2} & \underline{3} & \underline{4} & \underline{5} & \underline{6}\end{array}$

5 Academic self-efficacy, T1, T2

$.50 *$

$.58^{*}$

.06

$.21 *$

$-.44^{*}$

$-.11$

$-.61 *-.20 *$

Note. Emotionality and worry are considered components of test anxiety tendency. Correlations from SEM: Time 1(T1) below the diagonal. T2 above the diagonal, only perspective-taking and self-efficacy at Time 2 (T2) were included in the SEM. * $p<.05$.

Our first hypothesis was that up to $20 \%$ of the student teachers would self-report test anxiety emotionality and worry. In fact, $18 \%$ of the 249 student teachers selected "rather true" or "completely true" on statements about the test anxiety component of emotionality at T1, while $28 \%$ of the 249 student teachers selected these values for the test anxiety component of worry. At T2, 19\% of the 249 student teachers indicated rather true or completely true to statements about the test anxiety component of emotionality, and $28 \%$ of the 249 student teachers selected these values about the test anxiety component of worry. Thus, the student teachers' experiences with emotionality were in line with expectations, but their experiences with worry were higher than assumed in our Hypothesis 1. 


\section{Acta Educationis Generalis \\ Volume 10, 2020, Issue 1}

Table 3 shows the standardized path coefficients, standard errors, and confidence intervals from the SEM.

Table 3

SEM results: standardized regression coefficients, standard errors and confidence intervals

\begin{tabular}{|c|c|c|c|c|c|c|c|c|c|c|c|c|c|c|c|}
\hline \multicolumn{6}{|c|}{ PT at T2 } & \multicolumn{5}{|c|}{ ASE at T2 } & \multicolumn{5}{|c|}{$\underline{\text { SSE }}$ at T2 } \\
\hline $\begin{array}{l}\text { Variables at } \\
\underline{\mathrm{T} 1}\end{array}$ & $\beta$ & $\underline{S E}$ & $p$ & $\underline{\mathrm{CI}_{1}}$ & $\underline{\mathrm{CI}_{u}}$ & $\underline{\beta}$ & $\underline{S E}$ & $p$ & $\underline{\mathrm{CI}_{1}}$ & $\underline{\mathrm{CI}_{u}}$ & $\beta$ & $\underline{S E}$ & $p$ & $\underline{\mathrm{CI}_{1}}$ & $\underline{\mathrm{CI}_{\underline{u}}}$ \\
\hline Emotionality & -.32 & .14 & .03 & -.60 & -.04 & -.37 & .18 & .05 & -.73 & .00 & .15 & .19 & .44 & -.23 & .52 \\
\hline Worry & .14 & .16 & .37 & -.17 & .44 & .27 & .21 & .20 & -.14 & .67 & -.34 & .23 & .14 & -.78 & .11 \\
\hline PT & .86 & .06 & $<.001$ & .75 & .98 & -.05 & .09 & .59 & -.22 & .13 & .02 & .08 & .79 & -.14 & .18 \\
\hline ASE & -.11 & .11 & .30 & -.33 & .10 & .94 & .16 & $<.0$ & 1.86 & .97 & -.15 & .14 & .26 & -.42 & .11 \\
\hline SSE & .30 & .13 & .02 & .04 & .55 & -.32 & .21 & .13 & -.72 & .09 & .94 & .17 & $<.00$ & 1.70 & 1.37 \\
\hline Age & -.09 & .09 & .32 & -.26 & .08 & .07 & .09 & .47 & -.11 & .24 & .08 & .08 & .31 & -.08 & .24 \\
\hline Gender & .10 & .07 & .16 & -.04 & .24 & -.20 & .08 & .01 & -.35 & -.05 & -.18 & .07 & .01 & -.33 & -.04 \\
\hline GPA & .08 & .07 & .25 & -.05 & .20 & -.35 & .07 & $<.0$ & $1-.48$ & -.22 & .03 & .07 & .72 & -.12 & .17 \\
\hline Semester & .11 & .08 & .14 & -.04 & .26 & .09 & .08 & .31 & -.08 & .25 & .00 & .08 & .99 & -.15 & .15 \\
\hline Courses & .02 & .07 & .75 & -.11 & .15 & -.12 & .10 & .24 & -.31 & .08 & .03 & .08 & .71 & -.12 & .17 \\
\hline Learning & .22 & .07 & $<.001$ & .07 & .36 & .12 & .07 & .10 & -.02 & .27 & .09 & .07 & .20 & -.05 & .24 \\
\hline Neuroticism & .30 & .14 & .04 & .02 & .58 & .08 & .18 & .68 & -.28 & .43 & .12 & .18 & .50 & -.23 & .47 \\
\hline
\end{tabular}

Note. Emotionality and worry are considered components of test anxiety tendency. $\mathrm{PT}=$ perspective-taking tendency, $\mathrm{ASE}=$ academic self-efficacy, SSE $=$ social selfefficacy, GPA = grade point average in school, courses $=$ number of attended courses, learning $=$ individual learning hours. Males were coded as 0 and females as 1 .

The results suggested a good fit between the assumed model structure and the structure found in the data: $\chi 2=1206.34, \mathrm{RMSEA}=.04, \mathrm{CI}=[.034, .045], \mathrm{CFI}=.95$, SRMR =.07. Statistically significant $(\alpha \leq .05)$ SEM results were as follows: We predicted negative relations between perspective-taking tendency and the test 


\section{Acta Educationis Generalis \\ Volume 10, 2020, Issue 1}

anxiety component emotionality but positive relations with the test anxiety component worry (Hypothesis 2). Student teachers who recalled more emotionality with regard to exams at T1 reported less perspective-taking at T2 compared to those who recalled less emotionality at T1. Worry at T1 did not significantly relate to perspective-taking at $\mathrm{T} 2$. We further assumed negative relations between emotionality and worry and academic and social self-efficacy (Hypothesis 3). Worry at $\mathrm{T} 1$ related positively, but not significantly to academic self-efficacy at $\mathrm{T} 2$. The relationship between worry at $\mathrm{T} 1$ and social self-efficacy at T2 was negative and statistically significant. Emotionality at T1 was negatively related to academic self-efficacy at $\mathrm{T} 2$, but was not significantly related to social self-efficacy at $\mathrm{T} 2$ (see Table 3 ).

\section{Discussion}

The presented research provides the first insights into the concurrent relationships between student teachers' test anxiety, perspective-taking, and selfefficacy tendencies using longitudinal data. That is important because previous findings suggest that student teachers and in-service teachers often tend to focus on their own actions rather than their students across different situations in class, suggesting relations to traits such as low perspective-taking tendency. Perspective-taking involves mentally moving attention away from oneself to other individuals (e.g. Author et al., 2018), which is necessary for learneroriented education (e.g. Kordts-Freudinger, 2017). It can be conceptualized as a situated response (e.g. Mattan et al., 2016) or personal tendency (e.g. Davis, 1980).

Due to previous findings (e.g. Barrows et al., 2013), we assumed that a high tendency to experience test anxiety among student teachers would predict a low perspective-taking tendency and low self-efficacy. If so, student teachers with test anxiety would likely focus on their own behavior rather than apply studentoriented teaching in practice teaching during their university studies. We focused on the two classical test anxiety dimensions - emotionality and worry (Szafranski et al., 2012; Zeidner, 1998). Our first assumption (1) was that $20 \%$ of student teachers self-reported experiencing test anxiety (i.e. emotionality and worry). The amount of student teachers' experienced emotionality supported our first assumption, but their experienced worry was with $28 \%$ above the expected $20 \%$. This result suggested that about a quarter of the student teachers might experience anxiety in class (e.g. Frenzel et al., 2016; Sinclair \& Ryan, 1987).

The second assumption (2) was that the two test anxiety components (emotionality, worry) at T1 would be related to low perspective-taking tendency at T2. Our results partially supported this hypothesis: Only student teachers with a high tendency to emotionality with regard to achievement tests exhibited a low perspective-taking tendency about five months later. We found a statistically not significant positive relationship between the test anxiety component worry and later perspective-taking tendency. We had expected a positive relationship 


\section{Acta Educationis Generalis \\ Volume 10, 2020, Issue 1}

because positive associations between worry and empathetic responses had been described in other studies using different methods (e.g. Zainal \& Newman, 2018).

Furthermore, we assumed (3) that the tendency to test anxiety would be negatively related to student teachers' self-efficacy. The relationships, that we found, supported the hypothesis of significant negative relations between the test anxiety component emotionality at $\mathrm{T} 1$ and academic self-efficacy at $\mathrm{T} 2$ or between worry at $\mathrm{T} 1$ and social self-efficacy at $\mathrm{T} 2$. We did not find significant relations between worry at $\mathrm{T} 1$ and academic self-efficacy at $\mathrm{T} 2$. The current results support the assumption of individual differences as antecedents of the non-affective outcome perspective-taking in the organizational model of empathic responses (Davis, 2018). Our findings offer new insights into student teachers' tendency to engage in interpersonal understanding.

\subsection{Limitations and implications for future research and educational practice}

There are several limitations which should be considered when discussing the current results. One limitation is that relatively few student teachers in the crosssection sample participated at both measurement points, yielding a relatively small sample size for longitudinal analyses $(n=249)$. There were statistically significant differences in gender, study program, grade point average, and number of study semesters between the undergraduates who participated twice and those who participated only once (for details, see Appendix A.1). For example, the students who provided longitudinal data reported a better mean grade point average in school than those who participated only once. Thus, it was a self-selected longitudinal sample with regard to gender, study program, and school achievement. However, we did not find statistical differences in emotionality, worry, perspective-taking, or self-efficacy between the longitudinal and cross-sectional samples.

Further limitations are the self-report measures. The self-reported nature of the data might have led to an overestimation of common variance and/or to measurement errors due to social desirability bias. Such bias could have been relevant for the student teachers' responses to the perspective-taking items because these items represent flexible social cognitions and may activate knowledge of social norms and self-reflection on socially desirable behavior. Of note, for the most part our findings provide support for our hypotheses on the relations between these components and perspective-taking, supporting findings from other studies using different methods (e.g. experimentally induced worry on reading-the-mind-in-the-eyes performance, Zainal \& Newman, 2018).

Moreover, the present study possessed some significant strengths despite these limitations. First, our study addressed a significant gap in research on student teachers' test anxiety and perspective-taking tendencies, with the latter being a possible antecedent of student teachers' later empathic responses to their students and student orientation in class. A second major strength lies in the 


\section{Acta Educationis Generalis \\ Volume 10, 2020, Issue 1}

study's longitudinal design, which allowed us to examine whether student teachers' tendency to test anxiety at $\mathrm{T} 1$ affected perspective-taking and selfefficacy assessed five months later at T2 (with these constructs assessed at T1 also included in SEM). Our study thus provides the first insights into the relationships between test anxiety and perspective-taking tendency at the latent level within SEM.

\section{Conclusions and implications for educational practice}

The obtained results give an explanation approach why student teachers focused rather on themselves than on school students in classes in previous research (e.g. Bilz, 2014). The perspective-taking tendency is important for teachers' student orientation. For educational practice in higher education, we suggest that mindfulness training programs (e.g. Roeser et al., 2012) might be offered to all student teachers at university. Those with a high tendency to experience the test anxiety component emotionality might benefit especially from learning mindfulness techniques that can be applied during an achievement situation. Interventions to reduce (student) teachers' anxiety or distress would be highly relevant to teachers' perspective-taking tendency, and for students who may then be able to positively change their social behavior (Singh, Lancioni, Winton, Karazsia, \& Singh, 2013) at university and in their lifelong professional learning as teachers (Geršicová \& Barnová, 2018; Tamášová, 2015; Ütkür, 2019).

\section{Acknowledgement}

This work has been supported by the Teacher Education Center at MartinLuther-University Halle-Wittenberg (no grant number). We are also grateful to Vivien Eichhoff who supported us in the project and to Keri Hartman for her feedback on a former version.

\section{References}

Bandura, A. (1977). Self-efficacy: toward a unifying theory of behavioral change. Psychological Review, 84, 191-215. http://dx.doi.org/10.1037/0033295X.84.2.191

Barnová, S., Tamášová, V., \& Krásna, S. (2019). The role of resilience in coping with negative parental behaviour. Acta Educationis Generalis, 9(2), 93-106. https://doi.org/10.2478/atd-2019-0010

Barrows, J., Dunn, S., \& Lloyd, C. A. (2013). Anxiety, self-efficacy, and college exam grades. Universal Journal of Educational Research, 1, 204-208. http://dx.doi.org/10.13189/ujer.2013.010310

Baron-Cohen, S., Wheelwright, S., Hill, J., Raste, Y., \& Plumb, I. (2001). The "reading the mind in the eyes" test revised version: a study with normal adults, and adults with Asperger syndrome or high-functioning autism. 


\section{Acta Educationis Generalis \\ Volume 10, 2020, Issue 1}

Journal of Child Psychology Psychiatry, 42, 241-251. http://dx.doi.org/ 10.1111/1469-7610.00715

Bilz, L. (2014). Are symptoms of anxiety and depression in children and adolescents overlooked in schools? Zeitschrift für Pädagogische Psychologie, 28, 57-62. https://dx.doi.org/10.1024/1010-0652/a000118

Bolger, N., \& Eckenrode, J. (1991). Social relationships, personality, and anxiety during a major stressful event. Journal of Personality and Social Psychology, 61, 440-449. https://dx.doi.org/10.1037/0022-3514.61.3.440

Davis, M. H. (1980). A multidimensional approach to individual differences in empathy. JSAS Catalog of Selected Documents in Psychology, 10, 85-94. https://www.uv.es/friasnav/Davis_1980.pdf

Davis, M. H. (2018). Empathy: A social psychological approach. New York: Routledge.

Farooqi, Y. N., Ghani, R., \& Spielberger, C. D. (2012). Gender differences in test anxiety and academic performance of medical students. International Journal of Psychology and Behavioral Science, 2, 38-43. https://dx.doi.org/ 10.5923/j.iijbs.20120202.06

Frenzel, A. C., Pekrun, R., Goetz, T., Daniels, L. M., Durkson, T. L., BeckerKurz, B., \& Klassen, R. M. (2016). Measuring teacher's enjoyment, anger, and anxiety: the teacher emotions scale (TES). Contemporary Educational Psychology, 46, 148-163. https://dx.doi.org/10.1016/j.cedpsych.2016.05.003

Gáborová, L. (2011). Humanistic psychology in the university preparation of future teachers. Acta Technologica Dubnicae, 1(2), 1-15. https://doi.org/ 10.1515/atd-2015-0041

Gehlbach, H. (2004). Social perspective taking: a facilitating aptitude for conflict resolution, historical empathy, and social studies achievement. Theory \& Research in Social Education, 32, 39-55. https://dx.doi.org/ 10.1080/00933104.2004.10473242

Gehlbach, H., \& Vriesema C. C. (2019). Meta-bias: a practical theory of motivated thinking. Educational Psychology Review, 1, 65-85. https://dx.doi.org/10.1007/s10648-018-9454-6

Geršicová, Z., \& Barnová, S. (2018). Personal and social training as a part of class teachers' lifelong learning. Acta Educationis Generalis, 8(2), 24-39. https://doi.org/10.2478/atd-2018-0009

Gerwing, T. G., Rash, J. A., Gerwing, A. M A., Bramble, B., \& Landine, J. (2015). Perceptions and incidence of test anxiety. The Canadien Journal for the Scholarship of Teaching and Learning, 6, Art. 3. https://dx.doi.org/ 10.5206/cjsotl-rcacea.2015.3.3

Goodman, R. (1997). The Strengths and Difficulties Questionnaire: a research note. Journal of Child Psychology \& Psychiatry, 38(5), 581-586.

Hodapp, V., Laux, L., \& Spielberger, C. D. (1982). Theorie und Messung der emotionalen und kognitiven Komponente der Prüfungsangst. Zeitschrift für Differentielle und Diagnostische Psychologie, 3(3), 169-184. 


\section{Acta Educationis Generalis \\ Volume 10, 2020, Issue 1}

Konrath, S., O'Brien, E., \& Hsing, C. (2011). Changes in self-reported empathy in American college students over time: a meta-analysis. Personality and Social Psychology Review, 15, 180-198. https://dx.doi.org/10.1177/ 1088868310377395

Kordts-Freudinger, R. (2017). Feel, think, teach - emotional underpinnings of approaches to teaching in higher education. International Journal of Higher Education, 6, 217-229. https://dx.doi.org/10.5430/ijhe.v6n1p217

Kunter, M., Baumert, J., \& Köller, O. (2007). Effective classroom management and the development of subject-related interest. Learning and Instruction, 17, 494-509. https://dx.doi.org/10.1016/j.learninstruc.2007.09.002

Mattan, B. D., Rotshtein, P., \& Quinn, K. A. (2016). Empathy and visual perspective-taking performance. Cognitive Neuroscience, 7, 170-181. https://doi.org/10.1080/17588928.2015.1085372

Malone, A., \& Bertsch, S. (2016). Pencils down: contributions to neuroticism's effect on test anxiety. North American Journal of Psychology, 18, 419-426.

Middendorff, E., Apolinarski, B., Becker, K., Bornkessel, P., Brandt, T., Heißenberg, S., \& Poskowsky, J. (2017). Die wirtschaftliche und soziale Lage der Studierenden in Deutschland 2016. 21. Sozialerhebung des Deutschen Studentenwerks durchgeführt vom Deutschen Zentrum für Hochschul- und Wissenschaftsforschung.

Mooradian, T. A., Davis, M. H., \& Matzler, K. (2011). Self-reported empathy and the hierarchical structure of personality. The American Journal of Psychology, 124, 99-109. https://dx.doi.org/10.5406/amerjpsyc.124.1.0099

Pekrun, R. (1984). An expectancy-value model of anxiety. In H. M. van der Ploeg, R. Schwarzer, \& C. D. Spielberger (Eds.), Advances in test anxiety research, Vol. 3, (pp. 53-72). Lisse, The Netherlands: Swets \& Zeitlinger.

Pekrun, R. (2006). The control-value theory of achievement emotions: assumptions, corollaries, and implications for educational research and practice. Educational Psychology Review, 18, 315-341. https://dx.doi.org/ 10.1007/s10648-006-9029-9

Pekrun, R., Lichtenfeld, S., Marsh, H. W., Murayama, K., \& Goetz, T. (2017). Achievement emotions and academic performance: Longitudinal models of reciprocal effects. Child Development, 88, 1653-1670. https://dx.doi.org/ 10.1111/cdev.12704

Rammstedt, B., Koch, K., Borg, I., \& Reitz, T. (2004). Entwicklung und Validierung einer Kurzskala für die Messung der Big-FivePersönlichkeitsdimensionen in Umfragen. ZUMA-Nachrichten, 55, 5-28. http://nbn-resolving.de/urn:nbn:de: 0168-ssoar-207618

Roberts, B. W., Luo, J., Briley, D. A., Chow, P. I., Su, R., \& Hill, P. L. (2017). A systematic review of personality trait change through intervention. Psychological Bulletin, 143, 117-141. https://dx.doi.org/10.1037/bul0000088

Roeser, R. W., Skinner, E., Beers, J., \& Jennings, P. A. (2012). Mindfulness training and teachers' professional development: an emerging area of research 


\section{Acta Educationis Generalis \\ Volume 10, 2020, Issue 1}

and practice. Child Development Perspectives, 6, 167-173. https://dx.doi.org/ 10.1111/j.1750-8606.2012.00238.x

Roick, J., \& Ringeisen, T. (2017). Self-efficacy, test anxiety, and academic success: a longitudinal validation. International Journal of Educational Research, 83, 84-93. https://dx.doi.org/10.1016/j.ijer.2016.12.006

Rosseel, Y. (2012). lavaan: An R package for structural equation modeling. Journal of Statistical Software, 48, 1-36. http://www.jstatsoft.org/v48/i02/

Rutkowski, L., \& Svetina, D. (2014). Assessing the hypothesis of measurement invariance in the context of large-scale international surveys. Educational and Psychological Measurement, 74, 31-57. https://dx.doi.org/10.1177/ 0013164413498257

Schaafsma, S. M., Pfaff, D. W., Spunt, R. P., \& Adolphs, R. (2015). Deconstructing and reconstructing theory of mind. Trends in Cognitive Sciences, 19, 65-72. https://dx.doi.org/10.1016/j.tics.2014.11.007

Scherer, K. R. (1984). On the nature and function of emotion: A component process approach. In P. Ekman (Ed.), Approaches to emotion. Hillsdale: Erlbaum.

Schwarzer, R., \& Jerusalem, M. (1999). Skalen zur Erfassung von Lehrer- und Schülermerkmalen: Dokumentation der psychometrischen Verfahren im Rahmen der Wissenschaftlichen Begleitung des Modellversuchs Selbstwirksame Schulen. Retrieved from http://www.psyc.de/

Shulman, L. S. (1987). Knowledge and teaching: foundations of the new reform. Havard Educational Review, 57, 1-22. https://dx.doi.org/10.17763/ haer.57.1 .j463w79r56455411

Sinclair, K. E., \& Ryan, G. (1987). Teacher anxiety, teacher effectiveness, and student anxiety. Teaching and Teacher Education, 3, 249-253. http://dx.doi.org/10.1016/0742-051X(87)90007-2

Singh, N. N., Lancioni, G. E., Winton, A. S., Karazsia, B. T., \& Singh, J. (2013). Mindfulness training for teachers changes the behavior of their preschool students. Research in Human Development, 10, 211-233. https://dx.doi.org/ $10.1080 / 15427609.2013 .818484$

Standing Conference of the Ministers of Education and Cultural Affairs of the Länder in the Federal Republic of Germany (2014). Standards für die Lehrerbildung: Bildungswissenschaften. Beschluss der Kultusministerkonferenz vom 16.12.2004 i. d. F. vom 12.06.2014, Anlage IV. Retrieved from https://www.kmk.org/kmk/information-in-english.html

Szafranski, D. D., Barrera, T. L., \& Norton, P. J. (2012). Test anxiety inventory: 30 years later. Anxiety, Stress, \& Coping, 25, 667-677. https://dx.doi.org/ $10.1080 / 10615806.2012 .663490$

Tamášová, V. (2015). Professional and career development of vocational subject teachers as a trend in the lifelong learning of teachers. Acta Technologica Dubnicae, 5(1), 1-20. https://doi.org/10.1515/atd-2015-0029 


\section{Acta Educationis Generalis \\ Volume 10, 2020, Issue 1}

Tamášová, V., \& Barnová, S. (2011). School climate as the determinant of the relationship between the level of students' resilience and school satisfaction. Acta Technologica Dubnicae, 1(1), 19-37. https://dx.doi.org/10.1515/atd2015-0029

Ütkür, N. (2019). Determination of the empathy levels of prospective classroom teachers: An example of the life skills teaching course. Acta Educationis Generalis, 9(3), 89-104. https://dx.doi.org/10.2478/atd-2019-0015

Uitto, M., Jokikokko, K., \& Estola, E. (2015). Virtual special issue on teachers and emotions in Teaching and Teacher Education (TATE) in 1985-2014. Teaching and Teacher Education, 50, 124-135. http://dx.doi.org/10.1016/ j.tate. 2015.05 .008

U.S. Department of Education (2019). Every Student Succeeds Act (ESSA). Retrieved from https://www.ed.gov/essa?src=rn

Van der Graaff, J., Branje, S., De Wied, M., Hawk, S., Van Lier, P., \& Meeus, W. (2014). Perspective taking and empathic concern in adolescence: gender differences in developmental changes. Developmental Psychology, 50, 881888. https://dx.doi.org/10.1037/a0034325

Van Droogenbroeck, F., \& Spruyt, B. (2015). Do teachers have worse mental health? Review of the existing comparative research and results from the Belgian Health Interview Survey. Teaching and Teacher Education, 51, 88100. https://dx.doi.org/10.1016/j.tate.2015.06.006

Wigfield, A., \& Eccles, J. S. (2000). Expectancy-value theory of achievement motivation. Contemporary Educational Psychology, 25, 68-81. https://dx.doi.org/10.1006/ceps.1999.1015

$\mathrm{Xu}$, J. (2017) The mediating effect of listening metacognitive awareness between test-taking motivation and listening test score: An expectancy-value theory approach. Frontiers in Psychology, 8:2201. https://dx.doi.org/10.3389/ fpsyg.2017.02201

Zainal, N. H., \& Newman, M. G. (2018). Worry amplifies theory-of-mind reasoning for negatively valenced social stimuli in generalized anxiety disorder. Journal of Affective Disorders, 227, 824-833. https://dx.doi.org/ 10.1016/j.jad.2017.11.084

Zee, M., \& Koomen, H. M. (2016). Teacher self-efficacy and its effects on classroom processes, student academic adjustment, and teacher well-being: A synthesis of 40 years of research. Review of Educational Research, 86, 9811015. https://dx.doi.org/10.3102/0034654315626801

Zeidner, M. (1998). Test anxiety: The state of the art. New York: Plenum Press. 


\section{Acta Educationis Generalis \\ Volume 10, 2020, Issue 1}

\section{Appendix A}

\section{A.1 Tests for possible differences between the included longitudinal data and the excluded cross-sectional data}

We conducted chi-squared tests to test for possible differences between the included longitudinal data and the excluded cross-sectional data (with respect to the frequencies of the variables for gender and study program). We then employed a multivariate one-way analysis of variance (MANOVA; predictor variables emotionality, worry, grade point average, study semester; outcome variables perspective-taking, self-efficacy) to expose differences between the longitudinal data included in the analysis (i.e., the undergraduates who participated twice) and the cross-sectional data excluded from the analysis (the undergraduates who participated only once).

Of the 935 undergraduates who reported their gender, $n=253$ undergraduates (79\% females) participated at both $\mathrm{T} 1$ and $\mathrm{T} 2$, while $\mathrm{n}=682$ (65\% females) participated at $\mathrm{T} 1$ or $\mathrm{T} 2$ only, $\chi^{2}=17.09, \mathrm{df}=3, \mathrm{p}=.001$. The student teachers were enrolled in several different study programs corresponding to the type of school at which they hoped to teach. Of the $n=936$ undergraduates who reported their study program and participated twice (once), 25\% (19\%) aimed to teach at an elementary school, $18 \%(20 \%)$ at a lower or middle-track secondary school, and $34 \%(35 \%)$ at an academic-track secondary school (Gymnasium), 11\% (11\%) aimed to teach students with special educational needs, and $0.4 \%(15 \%)$ were enrolled in another study program (e.g., law, medicine), $\chi^{2}=78.72, \mathrm{df}=13$, $\mathrm{p}<.001$. Thus, there were statistically significant differences in the distribution of gender and study program between the undergraduates who participated twice and those who participated only once.

The one-way MANOVA with Bonferroni adjusted p-values showed no statistically significant differences between the two groups of students in emotionality Mattend_twice $=3.00$ /Mattend_once $=2.98, \quad$ SDattend_twice $=.92 /$ SDattend_once $=.95, \mathrm{~F}(1,921)=0.05$; worry Mattend_twice $=3.39 /$ Mattend_once $=3.30$, SDattend_twice $=.87 /$ SDattend_once $=.90, \mathrm{~F}(1,921)=1.78$; perspectivetaking Mattend_twice $=3.91 /$ Mattend_once $=3.88$, SDattend_twice $=.57 / \mathrm{S}$ Dattend_once $=.70, \quad \mathrm{~F}(1,921)=0.89$; academic self-efficacy Mattend_twice $=3.61 /$ Mattend_once $=3.64$, SDattend_twice $=.53 / \mathrm{SD}$ attend_once $=.44, \mathrm{~F}(1,921)$ $=0.92$; or social self-efficacy Mattend_twice $=3.65 /$ Mattend_once $=3.67$, SDattend_twice $=.42 / \quad$ SDattend_once $=.52, \quad F(1, \quad 921)=0.13$. There were significant differences in grade point average Mattend_twice $=2.09$ / Mattend_once $=2.18$, SDattend_twice $=.52 / \mathrm{SD}$ attend_once $=.56, \mathrm{~F}(1,921)=5.61$, $\mathrm{p}<.02$, and study semester Mattend_twice $=4.83$ /Mattend_once $=6.05$, SDattend_twice $=2.77 / \mathrm{SD}$ attend_once $=.3 .98, \mathrm{~F}(1,921)=19.84, \mathrm{p}<.001$. These differences between the full sample and subsample used in the longitudinal analyses will be taken up again in the discussion section. 


\section{A.2 Complete list of measures used in the longitudinal survey (in alphabetical order for current purposes; in randomized order in survey).}

\section{Measure}

Current statisfaction (Mittag, 1999)

Experienced sense in study (Schnell \& Becker, 2007)

Live satisfaction (Daig et al., 2011)

Neuroticism (Rammstedt et al., 2004)

Personal belief in a just world (Dalbert, 1999)

Procrastination (Schwarzer \& Jerusalem, 1999)

Self-efficacy (Schwarzer \& Jerusalem, 1999)

Study contents satisfaction (Schiefele \& Jacob-Ebbinghaus, 2006; Spörer \& Brunstein, 2005)

Subjectively experienced life quality (new developed scales)

Tendency to perspective-taking (Davis, 1980)

Test-anxiety (Hodapp et al., 1982; Schwarzer \& Jerusalem, 1999)

\section{Resources}

Daig, I., Spangenberg, L., Henrich, G., Herschbach, P., Kienast, Th. \& Brähler, E. (2011). Alters- und geschlechtspezifische Neunormierung der Fragen zur Lebenszufriedenheit (FLZM) für die Altersspanne von 14 bis 64 Jahre. Zeitschrift für Klinische Psychologie und Psychotherapie, 40(3), 172-178. Göttingen: Hogrefe.

Dalbert, C. (1999). The world is more just for me than generally: About the Personal belief in a Just World Scale's validity. Social Justice Research, 12, 79-98.

Davis, M. H. (1980). A multidimensional approach to individual differences in empathy. JSAS Catalog of Selected Documents in Psychology, 10, 85-94. https://www.uv.es/friasnav/Davis_1980.pdf

Hodapp, V., Laux, L., \& Spielberger, C. D. (1982). Theorie und Messung der emotionalen und kognitiven Komponente der Prüfungsangst. Zeitschrift für Differentielle und Diagnostische Psychologie, 3(3), 169-184.

Mittag, W. (1999). Skala Augenblickliche Zufriedenheit (SATIS) [Momentary satisfaction scale]. In Schwarzer, R., \& Jerusalem, M. (1999). Retrieved from http://www.psyc.de/

Rammstedt, B., Koch, K., Borg, I., \& Reitz, T. (2004). Entwicklung und Validierung einer Kurzskala für die Messung der Big-FivePersönlichkeitsdimensionen in Umfragen. ZUMA-Nachrichten, 55, 5-28. http://nbn-resolving.de/ urn:nbn:de:0168-ssoar-207618

Schiefele, U. \& Jacob-Ebbinghaus, L. (2006). Lernermerkmale und Lehrqualität als Bedingungen der Studienzufriedenheit. Zeitschrift für Pädagogische Psychologie, 20, 199-212. https://doi.org/10.1024/1010-0652.20.3.199 


\section{Acta Educationis Generalis \\ Volume 10, 2020, Issue 1}

Schnell, T. \& Becker, P. (2007). Der Fragebogen zu Lebensbedeutungen und Lebenssinn (LeBe). Göttingen: Hogrefe.

Schwarzer, R., \& Jerusalem, M. (1999). Skalen zur Erfassung von Lehrer- und Schülermerkmalen: Dokumentation der psychometrischen Verfahren im Rahmen der Wissenschaftlichen Begleitung des Modellversuchs Selbstwirksame Schulen. Retrieved March 24, 2019, from http://www.psyc.de/

Spörer, N., \& Brunstein, J. C. (2005). Strategien der Tiefenverarbeitung und Selbstregulation als Prädiktoren von Studienzufriedenheit und Klausurleistung. Psychologie in. Erziehung und Unterricht, 52, 127-137. 